\title{
Ten challenges for computer models in transitions research: Commentary on Holtz et al.
}

Published in Environmental Innovation and Societal Transitions

Final version available at: $\underline{\text { doi:10.1016/j.eist.2016.07.001 }}$

Authors: Will McDowall ${ }^{a}$ Frank W. Geels ${ }^{b}$

\author{
Affiliations: \\ ${ }^{a}$ UCL Institute for Sustainable Resources, 14 Upper Woburn Place, London, WC1H ONN, UK. \\ Email: w.mcdowall@ucl.ac.uk (corresponding author). \\ ${ }^{\mathrm{b}}$ Manchester Business School, Harold Hankins Building-6.01, The University of Manchester, \\ Manchester, M13 9PL, UK
}

\begin{abstract}
The emergence of a dedicated modelling community within the transitions field is to be welcomed, and the authors of a recent paper in EIST (Holtz et al. 2015) make many valuable points. We build on their position paper in two ways. First, we reflect on some of the ways in which modelling in other areas of 'sustainability science' has sometimes fallen short of the strengths articulated. Second, we extend some of Holtz et al.'s discussion of the epistemological and ontological challenges for modelling transitions. We suggest ten challenges in response to the more optimistic claims made by Holtz et al., and we provide some additional suggestions for ways forward. In particular, we suggest that seeking closer integration of qualitative, socio-technical analysis with models may not always be the best strategy. Rather, pluralist 'bridging strategies' and dialogue between analytic approaches may be more productive.
\end{abstract}

Keywords: modelling; socio-technical transitions; scenarios; process theory; interdisciplinarity

\section{Introduction}

The transitions community has traditionally relied on detailed case studies, of both historical transitions and current policy and innovation developments. Now, it is refreshing to see the emergence of a dedicated modelling community within the transitions field. The authors of a recent paper in EIST (Holtz et al. 2015) make many valuable points, and the emergence of this community within the wider transitions field is to be welcomed. In particular, it is exciting to see the efforts of modellers to grapple with the co-evolutionary, multi-agent character of transitions, which contrasts favourably with dominant modelling traditions such as CGE (Computable General Equilibrium), IAMs (Integrated Assessment Models) or linear optimisation.

However, along with the enthusiasm of opening up new research space, it is important not to overstate the benefits of models for transition research. The strengths of modelling are well articulated by Holtz et al., as are some of the limitations. We seek to build on their position paper in two ways. First, we reflect on some of the ways in which the use and development of models in 
other areas of 'sustainability science' has sometimes fallen short of the strengths articulated, and has sometimes obscured key issues. Second, we extend some of Holtz et al.'s discussion of the epistemological and ontological challenges for modelling transitions. Hence, it is in the spirit of constructive engagement that we suggest ten challenges in response to the more optimistic claims made by Holtz et al. for using system models in transition research, and we provide some additional suggestions for ways forward. Our ten challenges were inspired by the Holtz et al. position paper, but they should not be read simply as a direct critique of Holtz et al., whose work we appreciate. Rather, these challenges are a critical response to a range of issues that the position paper raised and that we have observed in related fields of modelling.

It is also important to note that Holtz et al., and other recent surveys of modelling in the transitions arena (e.g. Li et al., 2015), make clear that that there is a rich diversity of modelling approaches being applied in the field, and that these are used for a variety of purposes. Not all of the challenges we raise apply directly to all types of models and all uses. In a similar manner to the Holtz et al. paper, we aim to set out issues that are of general relevance to the transitions modelling community.

\section{Operational challenges for modelling transitions: lessons from related fields}

1) Hidden assumptions remain: We agree with Holtz et al. that modelling requires explicit recording of key assumptions, and that the process of developing models can be a valuable way to create greater precision and clarity about such assumptions. But it is an overstatement to say that it requires making "all" assumptions explicit. In practice, many assumptions can remain 'backgrounded' and hidden, either because they are not properly documented, or because they are implicit assumptions that have not been recognised even by the modellers themselves (Kloprogge et. al 2011; Miller 2015). Many such assumptions are inevitably subjective judgements made under uncertainty (Funtowicz and Saltelli 2014; Kloprogge et al. 2011), often unconsciously (Craig et al. 2002), and they carry the perspectives, assumptions and values of the modellers who make them. Publishing source code and data is helpful (see, e.g. (DeCarolis et al. 2012), but it remains important not to overstate the extent to which model-building and application clarifies the epistemic ground on which we stand.

2) Ambiguity in interpretation is important. There is a basic ambiguity in the relationship of a model to the real world (Beven 2009; Hennig 2010), and model interpretation thus requires reasoned (and subjective) judgement (Huntington et al. 1982; Sugden 2009). This ambiguity should not simply be consigned to a footnote (as in Holtz et al.), since doing so misrepresents the importance of subjective judgement in the process of learning from models. Cartright (2009) discusses very different possible interpretations of models when used as 'experiments', with different epistemic claims and underlying assumptions. The point here is that ambiguity about the nature of the claims, and the process of interpretation, has important implications for how models should be used. Yet sustained attention to such issues is lacking in many areas of modelling in social science (see, e.g. Rodrik 2014; Lorenz 2009), despite the readiness of analysts to apply models to policy questions. We 
therefore encourage greater reflection on the process of model interpretation, the nature of the knowledge generated through modelling, and the implications for application of models to policy questions.

3) Uncertainty analysis frequently downplays the remaining uncertainties (Funtowicz and Saltelli 2014). In particular, modelling in related fields has frequently not acknowledged the importance of ignorance (Stirling 1999), including 'meta-ignorance' (an inability to know the limits of our knowledge; Spiegelhalter and Riesch 2011). State-of-the-art methods for dealing with uncertainty help, yet at the same time such methods are often deployed as part of a narrative repertoire that serves to downplay the uncertainty and ignorance that remains. We thus agree that while one can use global sensitivity testing to understand how robust our options are in the face of many of the uncertainties, we should not assert, as Holtz et al. do, that we can do so in the face of the many uncertainties, i.e. it must be recognised that such efforts are partial, and not definitive.

4) Validation may be impossible for predictive applications of models (Hodges and Dewar 1992). Holtz et al. recognise this, by discussing the way in which the validity of models for future projections may be unknown. Issues of validation have been a vexed question for a range of types of models applied in the broad field of sustainability science, with differing definitions revealing a variety of underlying beliefs about what constitutes validity, how it should be established (David 2009, Ormerod and Rosewell 2009), and how different model uses impose different validation requirements (Windrum et al., 2007). Much like the concerns about the epistemic claims that can be legitimately derived from models (discussed under point 2 ), challenges in validating models have strong implications for the way in which models should be used in policy processes. Unfortunately, experience from other domains (such as mainstream economics, IAMs and energy system modelling) suggests that concerns about the extent to which quantitative models are or are not validated are often put in the background of policy advice that derives from such models. We therefore welcome the attention to validation issues highlighted by Holtz et al., but we urge future work to acknowledge the implication: that models that cannot be validated should be used and presented with caution and humility.

5) Models in stakeholder processes: facilitating dialogue, or closing it down? We largely agree that linking stakeholder engagement processes with modelling can be fruitful, both in enabling mutual social learning among stakeholders during model-building, and also by improving models themselves. However, there is a need for caution about how such processes are structured, and what claims are made arising from them (Stirling 2008). If output from such a process is a model and model results, what mechanisms are there for representing the perspectives of stakeholders whose views could not be straightforwardly parameterised or represented within the model structure? To what extent does the process of model building constrain and close down the modes through which participants are able to express diverse perspectives? To what extent does it thus delegitimise these positions? Zeiss and van Egmond have observed that, when models are built as part of a decisionmaking process, they can provide space for 'negotiation' between different domains (Zeiss and van Egmond 2014); yet they also note that model construction can be considered as an early phase of the decision-making process, one that is often obscured from wider scrutiny. In the context of integrated assessment modelling, Schneider noted that modelling can obscure different 
perspectives, and "diminish the openness of the decision-making process" (Schneider 1997, p. 230), rather than clarify it.

6) We must recognise the instrumental pressures at work. Like many forms of knowledge production, the results of numerical models can become divorced from the nuances of their production and used to justify political positions (Hertin et al. 2009; Craig et al. 2002). Many have argued that quantitative models are uniquely attractive to policymakers because they often appear to provide objectivity (Porter 1995; Robinson 1992). This has two specific implications. First, modellers should be cautious about over-promising, despite the attractions of policy influence and status that often come with confident projections. A core risk with apparently crisp quantitative tools is "the risk of finding (or being offered) answers... and believing them - even for questions that cannot be answered, now or perhaps ever" (Parson 1996, p. 320). Second, modellers should keep instrumental rationales clearly distinct from scientific (or epistemic) rationales. It is common among modellers in some fields, and illustrated in Holtz et al., to see modelling decisions made because they help to build "trust" or "credibility" in the model and its outputs. Building trust (an instrumental rationale) may be desirable, but it should typically be a second-order concern ${ }^{1}$ to the validity and substantive usefulness of the model itself (i.e. the epistemic value of the model), and these rationales should be distinct (Kloprogge et al. 2011).

\section{Fundamental challenges in modelling transitions: epistemic and ontological concerns}

7) Some characteristics of the topic of transitions are difficult to model. Holtz et al. acknowledge that the phenomenon of societal transitions has characteristics that may be difficult to model, but in our view they downplay the depth of these challenges. For instance, qualitative dimensions such as cultural meanings, interpretations, identities, institutions, conflicts and power struggles, which are crucial in societal transitions, are very difficult to parametrise and model. This means that a broad set of general theories and explanations are excluded from models, e.g. interpretivism, structuralism, relationism, and conflict theories (Geels 2010). Furthermore, it is difficult for models to account for structural changes that characterize transitions: "the parameters for judging the performance of systems themselves will change. Systems may also change their structure, i.e. their functional architecture of parameters" (Bai et al. in press). Last, but not least, models face difficulties in addressing 'wicked systems' (Andersson et al. 2014) that are characterized by both complicatedness (large number of interacting 'components') and complexity (where interactions may lead to 'emergence' and new kinds of patterned behaviour). Andersson et al. (2014) suggest that societies and eco-systems score high on both dimensions (Figure 1). They further suggest that complexity science (and associated models such as Agent Based Modelling) may be good in addressing complex, but not complicated systems (e.g. herds, crowds). They also suggest that system theories and associated models (e.g. system dynamics models, Integrated Assessment Models) may be good in addressing complicated, but not complex systems (Figure 2). Andersson et

\footnotetext{
${ }^{1}$ We note with thanks the suggestion of a reviewer that there may be occasions in which maintaining stakeholder engagement, and hence building trust, is more important than the scientific credibiity of a partiuclar assumption.
} 
al. (2014) thus conclude that formal modelling approaches have intrinsic limitations for analysing societal transitions. In fact, they suggest that 'narrative theories' are more suited for analysing such transitions, because they can "handle a number of key characteristics of wicked systems such as their heterogeneity, their contingency and their multilevel nature" (p. 154).

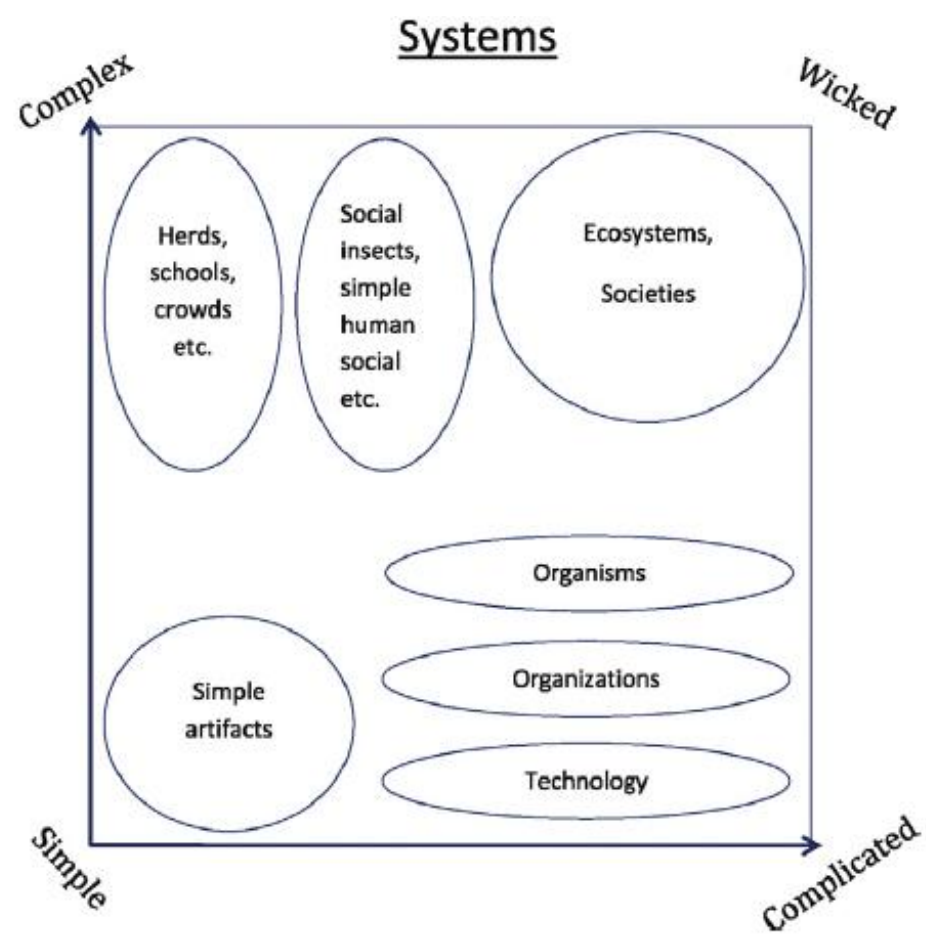

Figure 1: Characterizing different systems based on complexity and complicatedness (Andersson et al. 2014: 149)

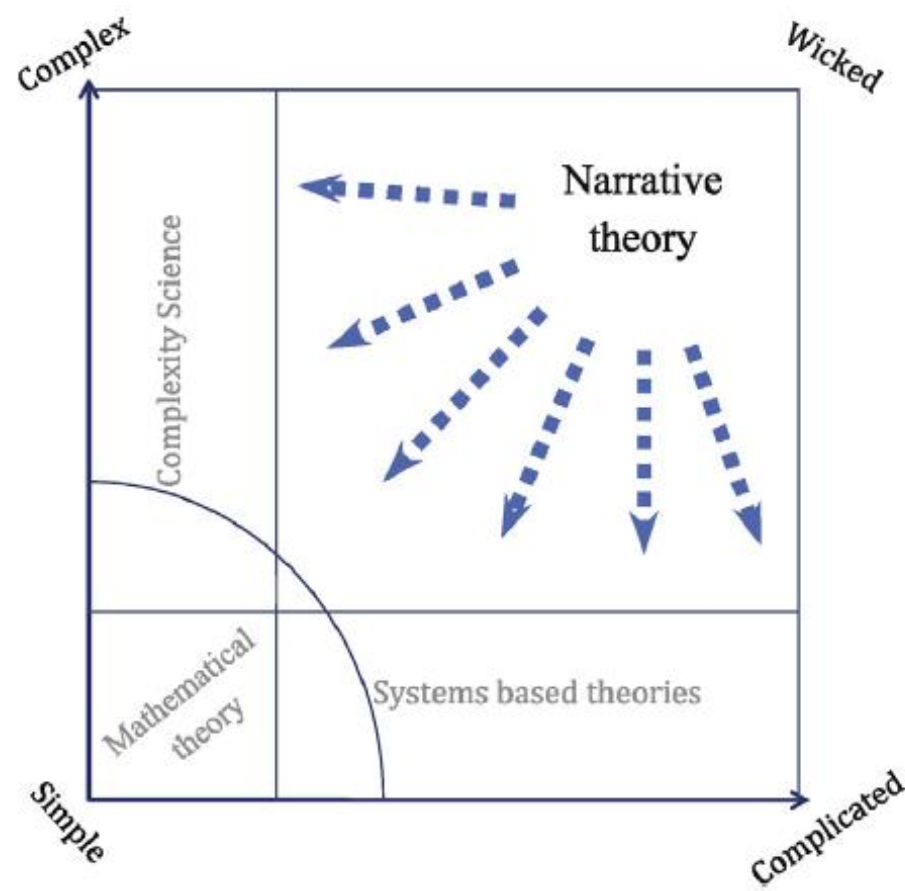

Figure 2: Mapping different analytical approaches (Andersson et al. 2014: 154) 
8) Epistemological challenges with regard to processual explanation. Another fundamental challenge is that many models offer a truncated way of analysing social processes. The transitions research field has been heavily informed by process explanations, as contrasted to variance explanations (Geels \& Schot 2010). The distinction, first elaborated by Mohr (1982) and since developed by Langley 1999, Poole et al. 2000, and others, emphasised the differences between approaches that explore statistical relationships between variables (the variance approach), and those that understand change as occurring as an unfolding process of events (the process approach). As this literature notes, many types of quantitative models embody or seek variance explanations of change, in which causal influences are exerted between different characteristics-of-things (variables), and in which the causal influences of one thing on another are understood to be largely fixed over time. Variance approaches are a fundamentally different way of explaining change compared to the process-based explanations characteristic of transitions thinking.

Process theories often provide 'narrative explanations' (Abell, 2004; Pentland, 1999) which can capture complex interactions between agency and changing contexts, time, event sequences, moves and countermoves, changing goals and identities. ${ }^{2}$

"Theorizing the social process via narrative is a deep tradition in both history and sociology. If there is any one idea central to historical ways of thinking, it is that the order of things makes a difference, that reality occurs not as time-bounded snapshots within which 'causes' affect one another (...), but as stories, cascades of events. And events in this sense are not single properties, or simple things, but complex conjunctures in which complex actors encounter complex structures. On this argument, there is never any level at which things are standing still. All is historical. Furthermore, there are no independent causes. Since no cause ever acts except in complex conjunctures with others, it is chimeral to imagine the world in terms of independent causal properties acting in and through independent cases" (Abbott, 2001: 227).

"Narrative explanation takes the form of an unfolding, open-ended story fraught with conjunctures and contingency, where what happens, an action, in fact happens because of its order and position in the story. Narrative therefore permits a form of sequential causation that allows for twisting, varied, and heterogeneous time paths to a particular outcome" (Griffin, 1993: 1099).

The quotes above suggest the rich narrative complexity of process-oriented styles of explanation, which seems appropriate for topics that are complex and complicated, as suggested by Andersson et al (2014). Yet is important to note that some forms of modelling-particularly the agent-based and system dynamics approaches that are well-represented among transition modellers-do come closer to a processual form of explanation, and are poorly represented by traditional views of 'variance' approaches (Langley 2007; Papachristos \& Amenides 2016; Van de Ven and Poole 2005). Indeed, some ABM and system dynamics proponents have emphasised the considerable divergence in explanatory approach between ABM, system dynamics modelling and classically 'variance'-based

\footnotetext{
${ }^{2}$ Narrative explanation (and process theory) thus aims to go beyond the traditional epistemological dichotomy of 'explanation' and 'understanding'.
} 
statistical approaches (e.g. Mingers 2000; Cedermann 2005; Miller 2015). Such process-oriented methods, which are well represented in the Holtz et al. paper, seem relatively better suited to transitions than those offering a more classically variance-based representation of change.

Yet even here, there are underlying differences between such process-oriented models and the narratively rich socio-technical studies. These differences are, for instance, well articulated by Langley's (2009) distinction between 'strong' and 'weak' forms of process theory. Langley distinguishes between process views that are "weak", i.e. focused on change and development of existing entities (things) and a "strong" process-based ontology, which sees things as temporary instances of processes-in-motion. Understood in this way, a socio-technical niche is not a 'thing' with measurable attributes that may influence the regime or ultimately the landscape, but rather it is continuously (re)created and (re)produced by a set of supportive processes. Viewed from this 'strong' process perspective, model-based process explanations often remain 'thin' (Langley 2007, p. 276), despite moving closer to a process-oriented style than classic variance-based approaches.

Similarly, Byrne and Callaghan (2013) distinguish between 'simple complexity', which understands collective outcomes as the emergent product of interactions between simple agents following prescribed decision rules, and 'complex complexity', which understand processes as recursive interactions between pre-existing structures and potentially creative actors, mediated by causal mechanisms (see also Andersson et al, 2014, discussed above). They associate the former with agent-based models, which offer an improved understanding of endogenous social processes compared to standard variance models. Nevertheless, these ABM-based understandings differ quite substantially from the non-linearities and twists and turns linked with 'complex complexity', which they suggest are better studied with narratives and "causal process tracing that provides a basis for understanding complex and contingent causation" (Byrne and Callaghan, 2013: 11-12). They suggest that most ABMs are based on atomic individualism (p. 45), which starts with actors and simple decision rules and then asks how structures can emerge. Since this ontology differs from sociological understandings of recursive interactions between agency and structure, they formulate the following challenge: "But any general complexity social science has to get beyond micro-determined emergence. It has to allow for structures with causal powers and it has to address human agency as capable of transcending narrow rules for behaviour" (p. 56).

These differing epistemological approaches, and their differing ontological foundations, create challenges for straightforward mapping of transition concepts into models of various kinds, including ABMs. Our intention here is not to say that this should not be attempted, but to highlight the challenges created by differences in the underlying views of change and how to understand it.

\section{9) Different philosophies of science and the limitations of positivism. Another fundamental} challenge for modellers relates to the variety of philosophies of science and research styles. Many models (especially in economics, system analysis, operations science) are rooted in a positivist philosophy of science, which assumes an independent objective world, with deterministic relations between variables that should be investigated with quantitative methods, experiments and model simulations (Table 2). Many scholars have discussed the limitations of positivism for understanding social change (e.g. Danermark et al. 2002; Sayer 1992; Flyvbjerg 2001; Kagan 2009). Scholars have therefore developed other philosophies of science, based on different assumptions of the nature of 
reality, epistemology and methodology (Table 2). Since societal transitions are complex processes, we suggest they can fruitfully be studied through different approaches and philosophies of science. The MLP, for instance, works from a critical realist approach, assuming a layered reality and aiming to identify causal mechanisms and patterns in transitions, which are studied as longitudinal event chains (e.g. Geels 2005). Transition scholars working from other scientfic styles have focused on asking normative questions, emancipating silenced voices, opening up debates to show multiplicity or hidden power structures (Genus and Coles 2008; Stirling 2008; Leach et al 2010).

\begin{tabular}{|c|c|c|c|c|}
\hline & Positivism & $\begin{array}{l}\text { Post-positivism, } \\
\text { critical realism }\end{array}$ & Constructivism & $\begin{array}{l}\text { Relativism, } \\
\text { postmodernism }\end{array}$ \\
\hline $\begin{array}{l}\text { Assumptions } \\
\text { about nature } \\
\text { of reality }\end{array}$ & $\begin{array}{l}\text { Reality is } \\
\text { independent and } \\
\text { objective (i.e. } \\
\text { empirical, } \\
\text { measurable). }\end{array}$ & $\begin{array}{l}\text { Reality is independent } \\
\text { and layered, consisting } \\
\text { of surface level } \\
\text { 'events', mediating } \\
\text { mechanisms, and } \\
\text { generative structures. }\end{array}$ & $\begin{array}{l}\text { Reality is socially } \\
\text { constructed through } \\
\text { intersubjective } \\
\text { meanings. }\end{array}$ & $\begin{array}{l}\text { There is no single } \\
\text { reality, but multiple } \\
\text { stories and narratives } \\
\text { of different realities. }\end{array}$ \\
\hline $\begin{array}{l}\text { Explanatory } \\
\text { goal and style }\end{array}$ & $\begin{array}{l}\text { Deterministic: } \\
\text { uncover general } \\
\text { laws and } \\
\text { relations between } \\
\text { variables (and } \\
\text { represent these } \\
\text { mathematically). }\end{array}$ & $\begin{array}{l}\text { Interpretive: Explain } \\
\text { processes by analysing } \\
\text { actions in the context } \\
\text { of structures, mediated } \\
\text { by causal mechanisms. }\end{array}$ & $\begin{array}{l}\text { Interpretive: describe } \\
\text { evolving meanings to } \\
\text { understand reality } \\
\text { construction. }\end{array}$ & $\begin{array}{l}\text { Critique dominant } \\
\text { narratives; uncover } \\
\text { hidden interests and } \\
\text { power structures; } \\
\text { emancipate the } \\
\text { silenced voices; raise } \\
\text { normative questions } \\
\text { (on justice, equity, } \\
\text { fairness). }\end{array}$ \\
\hline Methodology & $\begin{array}{l}\text { Experiments, } \\
\text { model } \\
\text { simulations, } \\
\text { manipulation of } \\
\text { variables and } \\
\text { quantitative data. }\end{array}$ & $\begin{array}{l}\text { Trace processes and } \\
\text { event chains } \\
\text { (quantitative or } \\
\text { qualitative); attempt to } \\
\text { infer causal } \\
\text { mechanisms and } \\
\text { deeper structures. }\end{array}$ & $\begin{array}{l}\text { 'Follow the actors' in } \\
\text { real-life contexts; } \\
\text { describe } \\
\text { interpretations, } \\
\text { disagreements and } \\
\text { (emerging) consensus. }\end{array}$ & $\begin{array}{l}\text { Reveal contradictions } \\
\text { and paradoxes; show } \\
\text { multiplicity and } \\
\text { alternatives; opening } \\
\text { up debates. }\end{array}$ \\
\hline $\begin{array}{l}\text { Typical } \\
\text { disciplines }\end{array}$ & $\begin{array}{l}\text { Mainstream } \\
\text { economics, } \\
\text { system analysis, } \\
\text { operations } \\
\text { sciences. }\end{array}$ & $\begin{array}{l}\text { Structuration theory; } \\
\text { neo-institutional } \\
\text { theory. }\end{array}$ & $\begin{array}{l}\text { Interpretive } \\
\text { (micro)sociology, } \\
\text { phenomenology, social } \\
\text { psychology. }\end{array}$ & $\begin{array}{l}\text { Critical theory, post- } \\
\text { structural sociology, } \\
\text { critical management } \\
\text { studies, critical } \\
\text { discourse theory, } \\
\text { cultural studies. }\end{array}$ \\
\hline
\end{tabular}

Table 2: Different philosophies of science (Geels et al., 2016: 578)

The philosophical position of Holtz et al. (2015) is somewhat ambivalent in our view. On the one hand, system dynamics and agent-based modellers have traditionally argued either that their approaches do not necessarily adhere to a particular philosophical position (Lane 2001), or that critical realism is an appropriate philosophical underpinning for such simulation (Mingers 2000, Miller 2015). This latter view is echoed in the transitions field by Papachristos and Adamides (2016), who explicitly advocate simulation modelling based on critical realist assumptions. On the other hand, we suggest that Holtz et al. (2015) display many features characteristic of positivism, such as a tendency to conflate causality with generality, an emphasis on experimentation and formalization; and an abstraction from specific contexts. Perhaps this ambivalence reflects the diversity of 
positions within the transition modelling community. In any case, our intention is to highlight that positivism is not the only scientific approach, to draw attention to some of postivism's underlying assumptions and associated blind spots, and to highlight the value of both plural approaches and critical reflection on such foundational assumptions. We suggest that there is value in further reflection on the underlying philosophical assumptions associated with the various modelling approaches, and how these assumptions relate to the transitions field.

10) Trade-offs between generality and context specificity in real-world transitions. The last challenge concerns the insensitivity of models to context and real-world specificities. This intrinsic challenge relates the modeller's goal of focusing on (presumed) core variables which are abstracted from concrete contexts and therefore have more generality. Latour (1999) nicely captured this intrinsic trade-off suggesting that 'reduction' and 'amplification' are part of the same process (Figure 3). On the one hand, the production of general knowledge requires the reduction of real-world complexity, which via several stages includes a loss of locality, specificity, and multiplicity. On the other, the process produces new dimensions, characterized as amplification, which include standardization, calculation and relative universality.

Holtz et al. recognize this trade-off, stating that "a single model therefore can hardly achieve the goals of completeness and detailedness" (p. 50), as do other transition modellers (e.g. Li et al. 2015). This has implications for the way in which models can be used in tandem with other forms of sociotechnical transition research, as we discuss in our conclusions. Moreover, there is a politics to a model's neglect of context, and a link to planning that often goes unacknowledged. In his book Seeing Like a State, Scott (1998) articulated some of the politics as follows: "The lack of context and particularity is not an oversight; it is the necessary first premise of any large-scale planning exercise. (...) Standardized citizens are uniform in their needs and (...) have, for the purpose of the planning exercise, no gender, no tastes, no history, no values, no opinions or original ideas" (p. 346). The point here is that specific modes of representation are not politically neutral, since they empower some perspectives and exclude others. As the transition modelling community grows and develops, we think there is value in further critical reflection on the ways in which such tools can and should be used, and normative and political dimensions to such use. 


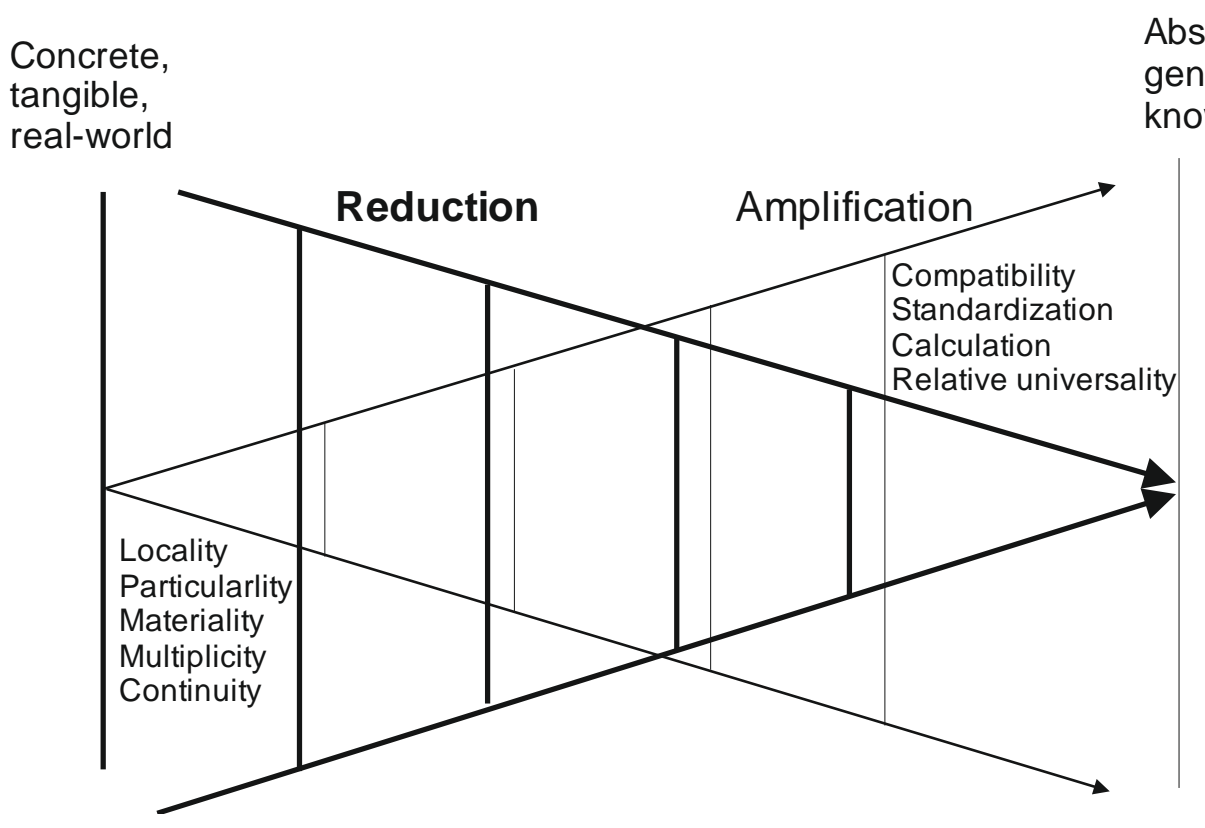

Figure 3: Two movements in the production of abstract general knowledge (adapted from Latour, 1999: 71)

\section{Conclusions}

In short, a number of fundamental characteristics make it difficult for all analytic approaches, including models, to represent transitions within a single encompassing framework or approach (see also Turnheim et al. 2015). The implications of these fundamental challenges are not that we should avoid models - far from it. As we emphasise, the emergence of the modelling community within the transitions field is an important step.

Holtz et al. identify numerous challenges and offer a variety of ways forward, including a call for more precise versions of the analytic frameworks such as the multi-level perspective to make them more amenable to modelling. Clearly greater precision can be helpful in avoiding ambiguity and conceptual confusion, but there are also risks in seeking simplification: one can think of key strengths of the MLP (such as generality and real-world accuracy) as traded off against the other criterion for good theory (simplicity) (Geels et al. 2016).

In light of the challenges we raise, we build on the position paper of Holtz et al. by suggesting a complementary way forward. Rather than emphasising integration of divergent analytic tools, we suggest that there is value in adopting an 'agonist-antagonist' mode of interdisciplinarity (Barry et al. 2008), in which we 'keep it complex' (Stirling 2010), and pursue plural and diverse approaches rather than integration and synthesis. A number of recent articles suggest ways in which this might be achieved, through establishing 'dialogue' and 'constructive conflict' between model-based scenarios and narrative scenarios or historical analogies (McDowall 2014; McDowall in press), and using pluralist 'bridging strategies' (Turnheim et al. 2015; Geels et al. 2016). Such approaches require mutual learning and cooperation on the part of both modellers and non-modellers within the transition field. 
In conclusion, we welcome the emergence of a modelling community within the transitions field. Holtz et al. have set out a strong agenda, and have highlighted many important issues and potential benefits and limitations for models in transition research and policy. Our comment has aimed to provide some additional suggestions for how to ensure that modelling transitions can reach its full analytic and practical potential.

\section{Acknowledgements:}

One of the authors would like to acknowledge support from the European Union's Seventh Framework Programme (FP7/2007-2013) under grant agreement no. 603942 (PATHWAYS).

\section{References}

Abbott, A. 2001. Time matters: On theory and method: University of Chicago Press.

Abell, P., 2004, 'Narrative explanation: An alternative to variance-centered explanation?', Annual Review of Sociology, 30, 287-310

Andersson, C., A. Törnberg, and P. Törnberg. 2014. Societal systems-complex or worse? Futures 63: 145-157.

Bai, X., S. van der Leeuw, K. O'Brien, F. Berkhout, F. Biermann, E. S. Brondizio, C. Cudennec, J. Dearing, A. Duraiappah, M. Glaser, A. Revkin, W. Steffen, and J. Syvitski. In Press. Plausible and desirable futures in the Anthropocene: A new research agenda. Global Environmental Change.

Barry, A., G. Born, and G. Weszkalnys. 2008. Logics of interdisciplinarity. Economy and Society 37(1): 20-49.

Beven, K. 2009. Environmental modelling: an uncertain future?: CRC Press.

Byrne, D. and Callaghan, G., 2013, Complexity Theory and the Social Sciences: The State of the Art, Routledge

Cartwright, N. (2009). If no capacities then no credible worlds. But can models reveal capacities? Erkenntnis, 70(1), 45-58.

Cederman, L. E. (2005). Computational models of social forms: Advancing generative process theory. American Journal of Sociology, 110(4), 864-893.

Craig, P., A. Gadgil, and J. Koomey. 2002. What can history teach us? a retrospective examination of long-term energy forecasts for the United States. Annual Review of Energy and the Environment 27: 83-118.

Danermark, B., M. Ekström, L. Jakobsen, and J. C. Karlsson. 2002. Explaining Society: Critical Realism in the Social Sciences: Routledge.

David, N. (2009). Validation and verification in social simulation: patterns and clarification of terminology. In F. Squazzoni (Ed.), Epistemological aspects of computer simulation in the social sciences (pp. 141-153). Berlin: Springer.

DeCarolis, J. F., K. Hunter, and S. Sreepathi. 2012. The case for repeatable analysis with energy economy optimization models. Energy Economics 34(6): 1845-1853.

Flyvbjerg, B. 2001. Making social science matter: Why social inquiry fails and how it can succeed again: Cambridge university press.

Funtowicz, S. O. and A. Saltelli. 2014. When all models are wrong. Issues in Science and Technology Winter 2014: 79-85.

Geels, F.W., 2005, 'Processes and patterns in transitions and system innovations: Refining the coevolutionary multi-level perspective', Technological Forecasting \& Social Change, 72(6), 681696 
Geels, F. W. 2010. Ontologies, socio-technical transitions (to sustainability), and the multi-level perspective. Research Policy 39(4): 495-510.

Geels, F. W. and J. Schot. 2010. Reflections: Process theory, causality and narrative explanation. In Transitions to Sustainable Development: New Directions in the Study of Long Term Transformative Change, edited by J. Grin, et al.: Routledge.

Geels, F.W., Berkhout, F. and Van Vuuren, D., 2016, Bridging analytical approaches for low-carbon transitions, Nature Climate Change, 6(6), 576-583

Griffin, L.J., 1993, 'Narrative, event-structure, and causal interpretation in historical sociology', American Journal of Sociology, 98(5), 1094-1133

Hennig, C. 2010. Mathematical Models and Reality: A Constructivist Perspective. Foundations of Science 15(1): 29-48.

Hertin, J., J. Turnpenny, M. Nilsson, D. Russel, and B. Nykvist. 2009. Rationalising the policy mess? Ex ante policy assessment and the utilisation of knowledge in the policy process. Environment and planning. A 41(5): 1185.

Hodges, J. S. and J. A. Dewar. 1992. Is it you or your model talking? a framework for model validation. RAND Corporation, Santa Monica. ISBN: 0-8330-1223-1.

Holtz, G., F. Alkemade, F. de Haan, J. Köhler, E. Trutnevyte, T. Luthe, J. Halbe, G. Papachristos, E. Chappin, J. Kwakkel, and S. Ruutu. 2015. Prospects of modelling societal transitions: Position paper of an emerging community. Environmental Innovation and Societal Transitions 17: 4158.

Huntington, H. G., J. P. Weyant, and J. L. Sweeney. 1982. Modeling for insights, not numbers: the experiences of the energy modeling forum. Omega 10(5): 449-462.

Kagan, J. 2009. The three cultures: Natural sciences, social sciences, and the humanities in the 21st century: Cambridge University Press.

Kloprogge, P., J. P. van der Sluijs, and A. C. Petersen. 2011. A method for the analysis of assumptions in model-based environmental assessments. Environmental Modelling and Software 26(3): 289-301.

Lane, D. C. (2001). Rerum cognoscere causas: Part I-How do the ideas of system dynamics relate to traditional social theories and the voluntarism/determinism debate? System Dynamics Review, 17(2), 97-118.

Langley, A. (1999). Strategies for theorizing from process data. Academy of Management review, 24(4), 691-710.

Langley, A. (2007). Process thinking in strategic organization. Strategic Organization, 5(3), 271-282.

Langley, A. (2009). Studying processes in and around organizations. In A. Bryman \& D. A. Buchanan (Eds.), Sage handbook of organizational research methods. (pp. 409-429). London: Sage.

Latour, B. 1999. Pandora's hope: essays on the reality of science studies: Harvard University Press.

Leach, M., Scoones, I. and Stirling, A., 2010, Dynamic Sustainabilities: Technology, Environment, Social Justice, Earthscan: London, Washington, DC

Li, F. G., E. Trutnevyte, and N. Strachan. 2015. A review of socio-technical energy transition (STET) models. Technological forecasting and social change 100: 290-305.

Lorenz, T. (2009). Abductive fallacies with Agent-Based Modeling and system dynamics. In F. Squazzoni (Ed.), Epistemological aspects of computer simulation in the social sciences (pp. 141-153). Berlin: Springer.

McDowall, W. 2014. Exploring possible transition pathways for hydrogen energy: A hybrid approach using socio-technical scenarios and energy system modelling. Futures 63, 1-14.

McDowall, W. in press. Are scenarios of hydrogen vehicle adoption optimistic? A comparison with historical analogies. Environmental Innovation and Societal Transitions.

Miller, K. D. (2015). Agent-Based Modeling and Organization Studies: A critical realist perspective. Organization Studies, 36(2), 175-196

Mingers, J. (2000). The contribution of critical realism as an underpinning philosophy for OR/MS and systems. Journal of the Operational Research Society, 51(11), 1256-1270. 
Mohr, L. (1982). Approaches to explanation: Variance theory and process theory. Explaining organizational behavior, 35-70.

Ormerod, P., \& Rosewell, B. (2009). Validation and verification of Agent-Based Models in the social sciences. In F. Squazzoni (Ed.), Epistemological aspects of computer simulation in the social sciences (pp. 130-141). Berlin: Springer.

Papachristos, G., \& Adamides, E. (2016). A retroductive systems-based methodology for sociotechnical transitions research. Technological forecasting and social change, 108, 1-14.

Parson, E. A. 1996. Three dilemmas in the integrated assessment of climate change. Climatic Change 34(3-4): 315-326.

Pentland, B.T., 1999, 'Building process theory with narrative: From description to explanation', Academy of Management Review, 24(4), 711-724

Poole, M. S., A. H. Van de Ven, K. Dooley, and M. E. Holmes. 2000. Organizational change and innovation processes: Theory and methods for research: Oxford University Press, New York, NY.

Porter, T. M. 1995. Trust in Numbers. Princeton: Princeton University Press.

Robinson, J. B. 1992. Of maps and territories: The use and abuse of socioeconomic modeling in support of decision making. Technological Forecasting and Social Change 42(2): 147-164.

Rodrik, D. (2015). Economics Rules: Why Economics Works, when it Fails, and how to Tell the Difference: OUP Oxford.

Sayer, A. 1992. Method in Social Science: A Realist Approach. London: Routledge.

Schneider, S. H. 1997. Integrated assessment modeling of global climate change: Transparent rational tool for policy making or opaque screen hiding value - laden assumptions? Environmental Modeling and Assessment 2(4): 229-249.

Scott, J. C. 1998. Seeing like a state: How certain schemes to improve the human condition have failed: Yale University Press.

Spiegelhalter, D. J. and H. Riesch. 2011. Don't know, can't know: Embracing deeper uncertainties when analysing risks. Philosophical Transactions of the Royal Society A: Mathematical, Physical and Engineering Sciences 369(1956): 4730-4750.

Stirling, A. 1999. The appraisal of sustainability: some problems and possible responses. Local Environment 4(2): 111-135.

Stirling, A. 2008. "Opening up" and "closing down": Power, participation, and pluralism in the social appraisal of technology. Science Technology and Human Values 33(2): 262-294.

Stirling, A. 2010. Keep it complex. Nature 468(7327): 1029-1031.

Sugden, R. 2009. Credible worlds, capacities and mechanisms. Erkenntnis 70(1): 3-27.

Turnheim, B., F. Berkhout, F. Geels, A. Hof, A. McMeekin, B. Nykvist, and D. van Vuuren. 2015. Evaluating sustainability transitions pathways: Bridging analytical approaches to address governance challenges. Global Environmental Change 35: 239-253.

Van de Ven, A. H., \& Poole, M. S. (2005). Alternative approaches for studying organizational change. Organization Studies, 26(9), 1377-1404.

Windrum, P., Fagiolo, G., \& Moneta, A. (2007). Empirical validation of agent-based models: Alternatives and prospects. Journal of Artificial Societies and Social Simulation, 10(2), 8.

Zeiss, R. and S. van Egmond. 2014. Dissolving decision making? Models and their roles in decisionmaking processes and policy at large. Science in Context 27(04): 631-657. 